\title{
Endophytic algae of Chondrus crispus (Rhodophyta). IV. Effects on the host following infections by Acrochaete operculata and A. heteroclada (Chlorophyta)*
}

\author{
Juan A. Correa ${ }^{1, * *}$, Jack L. McLachlan ${ }^{2}$ \\ 'Department of Biology, Dalhousie University, Halifax, Nova Scotia, Canada B3H 4J1 \\ ${ }^{2}$ National Research Council of Canada, 1411 Oxford St., Halifax, Nova Scotia, Canada B3H $3 Z 1$
}

\begin{abstract}
The rhodophycean seaweed Chondrus crispus was infected under laboratory conditions by the green algal endophytes Acrochaete operculata and A. heteroclada. Such infections resulted in detrimental effects on host performance, including slower growth and carrageenan yields. Regeneration capacity of the host was diminished, with the extent determined by the density of the infection. Infections also caused softening of host tissue in both laboratory-infected and wild fronds; in the former the degree of softness was directly related to density of infections. Infected $C$. crispus was preferred over non-infected material when offered to Idotea baltica and Gammarus oceanicus, and the consumption of infected fronds was similar to that of the highly palatable chlorophyte Ulva sp. In general, infection by $A$. heteroclada affected the 2 life-history generations of the host similarly, whereas A. operculata affected mainly sporophytic fronds. This study shows that $A$. operculata and $A$. heteroclada are pathogens of $C$. crispus, and that their effects on the host, either as primary cause of dysfunctions or as agents facilitating secondary infections by other pathogens, can have major effects on both natural and cultivated populations
\end{abstract}

\section{INTRODUCTION}

Marine macroalgae host a large diversity of organisms, and the majority occur as epiphytes (Wahl 1989). Effects on hosts are determined by the nature of the epibiont, the densities at which they occur and parts of the host infected.

Epiphytized individuals are in general disadvantaged (Wahl 1989) because of added weight (Oswald \& Seed 1986), which alters some mechanical properties of the thallus (Dixon et al. 1981), including surface friction and drag (D'Antonio 1985), chemical changes at the host-epiphyte interface (Terry \& Edyvean 1981). and competition for light and nutrients (Sand-Jensen 1977, Sand-Jensen \& Revsbech 1987, Carpenter 1990).

\footnotetext{
- NRCC No. 33017

- Present address: Departamento de Ecología, Facultad de Ciencias Biológicas, P. Universidad Católica de Chile Casilla 114-D, Santiago, Chile
}

Additional negative effects on the host may result from 'accidental' grazing by herbivores eating epiphytes (Shacklock \& Doyle 1983, D'Antonio 1985). On the other hand, algal hosts may possibly benefit from epiphytes (Ducker \& Knox 1984)

Macroalgae also host a variety of algal endophytes, some of which are non-photosynthetic (parasitic) and obtain nutrients from their hosts (Goff 1982). Photosynthetic species of Chlorophyta, Phaeophyta and Rhodophyta occur as endophytes and appear to be carbon-independent of their hosts (Correa et al. 1988, Correa 1990). Little is known about how algalsymbionts affect their hosts at an organismic level. In parasitic associations for example, research has concentrated on assessing changes in the host at the cellular level (Kugrens \& West 1973, Goff 1976), or in detecting translocation of substances between partners (e.g. Court 1980, Kremer 1983). Kremer (1983) suggested that infection by even several individuals of the parasite Harveyella mirabilis (Reinsch) Schmitz \& 
Reinke did not affect the vitality of the host, Rhodomela confervoides (Huds.) Silva. There are, though, indications that parasitized hosts are less vigorous, have fewer growing tips and are more susceptible to removal from the population following local tissue destruction (Goff 1976). Two studies have specifically evaluated the effects of algal parasitic infections on the host, and these demonstrated reduced growth rates and elongation of the host thallus (Nonomura 1979, Apt 1984).

Knowledge of the effects of pigmented endophytic species on algal hosts is also incomplete. Most studies have focussed on life histories and morphologies of the endophytes (e.g. Nielsen 1979, O'Kelly 1982, Tam et al. 1987), and it has been suggested that some acrochaetioid endophytes do not interfere with the host (Tam et al. 1987). Nevertheless, ectocarpoid endophytes have overgrown frond discs of Laminaria digitata (Hudson) Lamouroux in culture (Russell 1983), and streblonemoids have been found associated with (Andrews 1977), and proven to be the cause of (Apt 1988), algal galls. The commercially valuable brown alga Undaria sp. hosts Streblonema-like endophytes that alter the texture of the fronds, which become thicker and coarser than non-infected tissue (Yoshida \& Akiyama 1979). The endophyte is considered a pathogen that, following heavy infection, reduces the quality of Undaria as food.

Chondrus crispus Stackh. is a red alga with isomorphic sporophytic and gametophytic life-history phases (Chen \& McLachlan 1972); both phases occur together in natural populations. This species is used commercially for extraction of carrageenan and ecologically it is one of the most important red algae in the western North Atlantic. C. crispus hosts a number of brown and green endophytes, although no red species have been reported (Nielsen \& McLachlan 1986. Correa et al. 1987), and the frequency of infection in natural populations is high (Correa et al. 1987). Many of the heavily infected fronds are broken, and this may indicate frond fracture following tissue weakening caused by endophytes. This view is supported by observations on laboratory-infected fronds of C crispus; these undergo significant cellular damage during infection by either Acrochaete operculata Correa et Nielsen or $A$. heteroclada Correa et Nielsen (Correa 1990), the 2 most common green endophytes recorded for this host. In this study, we have experimentally evaluated the effects of infections by the 2 green endophytes on growth, carrageenan yield and regeneration capacity of the host. Toughness was quantified to assess whether the cellular damage observed by Correa (1990) was correlated with changes in physical properties of the fronds. Food preference and edibility trials were undertaken to assess the effect of infections on the acceptability of $C$. crispus as food by 2 common crustacean grazers.

\section{MATERIALS AND METHODS}

Cultures either of non-infected sporophytic or gametophytic Chondrus crispus (isolate $\mathrm{BH}$ ), or of material of the same host isolate infected by Acrochaete operculata (isolate PF1a 161085) or $A$. heteroclada (isolate PC2V 300585) (Correa 1990), were made from laboratory stocks, Ulva sp., provided by L. Staples (NRCC field station, Finck Cove, NS, Canada), was fieldcollected.

Growth and carrageenan yield. The effect of infections by Acrochaete operculata and A. heteroclada on growth, expressed as biomass accumulation, in sporophytic and gametophytic fronds of Chondrus crispus, was assessed in an experiment with 4 combinations, each consisting of 1 species of endophyte infecting 1 phase of the host. Each combination was done at a different time because of space constraints. Stocks of infected material were established at least $6 \mathrm{wk}$ prior to the experiment and maintained under conditions of slow growth: 8 to $10^{\circ} \mathrm{C},<10 \mu \mathrm{mol} \mathrm{m} \mathrm{m}^{-2} \mathrm{~s}^{-1}$ photon flux density (PFD) and a $12 \mathrm{~h}$ light period. Apical segments of $C$. crispus, 5 to $10 \mathrm{~mm}$ in length and endophytic densities $<500$ cells $\mathrm{mm}^{-2}$ in the $A$. operculatasporophyte combination, were excised from the tip of the fronds. The endophyte in the $A$. operculatagametophyte combination remained localized near the penetration site (Correa et al. 1988, Correa 1990), and areas with the heaviest infection, $>50 \%$ of the host surface occupied by coalescing lesions, were selected from stock cultures. As these infections were always located at the base of large fronds, excised fragments lacked an apical meristem. Prior to the experiment, these fragments were incubated for at least $20 \mathrm{~d}$ at 45 to $50 \mu \mathrm{mol} \mathrm{m} \mathrm{m}^{-2} \mathrm{~s}^{-1} \mathrm{PFD}, 12 \mathrm{~h} \mathrm{~d}^{-1}$, and $15^{\circ} \mathrm{C}$ to allow regeneration of apical meristems. $A$. heteroclada develops a polystromatic habit within the outer cell wall of the host, initially with little penetration into the cortex (Correa et al. 1988, Correa 1990). Excised apical segments of $C$. crispus had infections concentrated in the basal region (ca $3 \mathrm{~mm}$ above the cut edge), and the density of infection was estimated to be less than $20 \%$ of the surface of the host occupied by $A$. heteroclada. The apical areas, including the meristem, were free from infecting filaments.

Each apex of Chondrus crispus was blotted, weighed and transferred into a numbered $250 \mathrm{ml}$ flask containing $175 \mathrm{ml}$ of enriched seawater medium SFC (Correa 1990). Thirty infected apices, one per flask, were used for each host-endophyte combination; controls were 30 non-infected apices. Each infected apex 
was paired with a control of similar shape and wet weight and inoculated into an individual flask. The 60 flasks for each host-endophyte combination were incubated on a single shelf in a growth chamber set at $15^{\circ} \mathrm{C}$ on a $16 \mathrm{~h}$ light period with 40 to $50 \mu \mathrm{mol} \mathrm{m} \mathrm{m}^{-2} \mathrm{~s}^{-1}$ PFD. The position of the paired flasks on the shelf was rotated at $10 \mathrm{~d}$ intervals to minimize effects of unevenness in illumination. Culture medium was changed at $10 \mathrm{~d}$ intervals and blotted wet weights were recorded every $20 \mathrm{~d}$. At the end of the experiments, the segments were dried at $70^{\circ} \mathrm{C}$ to constant weight and stored for carrageenan extraction.

Differences in initial weights among replicates were normalized; the biomass accumulated during each time interval $(t)$ was calculated for individual segments using the expression $\left(W_{t}-W_{0}\right) / W_{0}$, where $W_{0}$ is wet weight at the beginning of the experiment and $W_{t}$ is weight of the same apex at time $t$. Independence of the variances from the means and homoscedasticity of variances were achieved by logarithmic transformation, after which $t$-tests for paired observations were applied (Sokal \& Rohlf 1981); no significant departures from normality were detected (Kolmogorov-Smirnov test, $p>0.05$ ).

Carrageenan was extracted following the procedure described by Craigie \& Leigh (1978). Carrageenan yield was divided by the weight of the sample before extraction and is expressed as a percentage.

Infection and regeneration. To determine the regenerative capacity in the presence of the endophyte, fragments of about $16 \mathrm{~mm}^{2}$ were excised from 3 areas along large sporophytic fronds infected in the laboratory with Acrochaete operculata. Fragments from the base of the fronds were heavily infected ( $>2000$ endophytic cells $\mathrm{mm}^{-2}$ ), those from central portions were moderately infected (500 to 1500 endophytic cells $\mathrm{mm}^{-2}$ ) and apical regions were less densely infected $\left(<100\right.$ endophytic cells $\left.\mathrm{mm}^{-2}\right)$. Fragments in which most of the cortex of the host had been replaced by the endophyte were not used. Approximately 20 fragments per flask were cultured in $250 \mathrm{ml}$ aeration flasks containing $200 \mathrm{ml}$ of SFC medium, and incubated at $15^{\circ} \mathrm{C}, 40$ to $50 \mu \mathrm{mol} \mathrm{m} \mathrm{m}^{-2} \mathrm{~s}^{-1} \mathrm{PFD}$ and a $16 \mathrm{~h}$ light period; the experiment lasted $30 \mathrm{~d}$ and the medium was changed weekly. Non-infected sporophytic fragments of equivalent areas were used as controls and cultured in parallel. At the end of the experiment, each fragment was observed under a dissection microscope and scored as positive regeneration if at least one upright emerged from any position on the fragment.

Fragments of gametophytic Chondrus crispus infected by Acrochaete operculata were designated as heavily infected $(>50 \%$ of the surface occupied by coalescing lesions); moderate (between 10 and $50 \%$ of their surfaces affected); or lightly infected $(<10 \%$ of the surface occupied by lesions). Controls, as non-infected gametophytic fronds, were subjected to the same experimental procedure used for the $A$. operculatasporophyte combination.

Levels of infection of Chondrus crispus by Acrochaete heteroclada were designated as above although there were no differences between sporophytic and gametophytic fronds (Correa et al. 1988, Correa 1990); non-infected control segments were as above, and the experimental procedure followed that for the A. operculata-sporophyte combination.

Infection and toughness. We define toughness as the degree of resistance of Chondrus crispus tissue to a penetrating device, and it was measured following the principles in Littler \& Littler (1980). The apparatus was a gelometer, described by Goring (1956) and modified by J. S. Craigie, fitted with a special sample holder (Fig. 1). The plunger descended at a constant speed, electronically controlled at $0.36 \mathrm{~mm} \mathrm{~s}^{-1}$, until it perforated the sample. The pressure exerted upon the sample was detected by a load cell, calibrated to either 100 or $500 \mathrm{~g}$, attached to a chart recorder Measurements were made away from sample margins, and when there was more than one measurement from a single sample, these were made at least $3 \mathrm{~mm}$ apart. When repeated measurements were taken, the sample was transferred to a Petri dish with fresh medium to

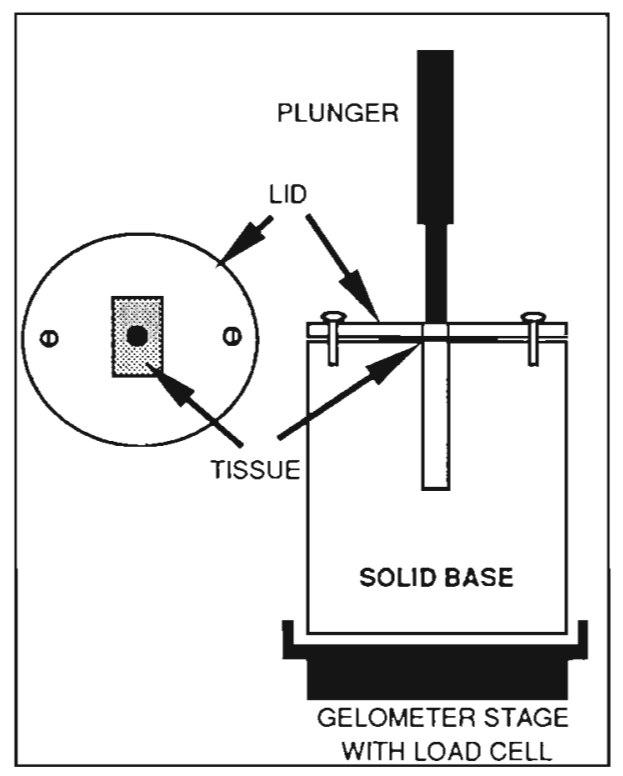

Fig. 1 Device used to assess toughness of Chondrus crispus. The sample holder is a cylinder of solid acrylic with a cylindrical hole, $1.5 \times 10 \mathrm{~mm}$, drilled in the center; the lid is of the same material, also with a $1.5 \mathrm{~mm}$ hole in the center. Samples are held between the base and the lid, secured by 2 bronze screws providing an even and gentle pressure on the tissue. The cylindrical plunger is $1 \mathrm{~mm}$ in diameter. The plunger was attached to the gelometer. The solid base rested on the stage of the gelometer where the load cell was located 
prevent desiccation between readings. Samples were immediately sectioned by hand (10 to $20 \mu \mathrm{m}$ thick) in the vicinity of each perforation, and their thickness measured under a microscope. The plunger did not tear the sample and discs of ca $1 \mathrm{~mm}$ in diameter were obtained. The diameter of the disc and the thickness at the perforation point are expressed, as normalized values, in $\mathrm{g} \mathrm{mm}^{-3}$.

Fragments of sporophytic fronds with different densities of Acrochaete operculata infection were tested for toughness. The degree of infection was based on the same criterion used in experiments on regeneration. Fragments whose cortex had been replaced by endophytic cells (i.e. terminal infection), as discernible by observation with a dissecting microscope, were also tested. Values of toughness obtained from noninfected fronds were used for comparison. All fronds were preconditioned for at least $3 \mathrm{wk}$ at $15^{\circ} \mathrm{C}, 40$ to $50 \mu \mathrm{mol} \mathrm{m} \mathrm{m}^{-2} \mathrm{~s}^{-1}$ PFD and a $16 \mathrm{~h}$ light period.

The effect of Acrochaete heteroclada infection was assessed for toughness on both sporophytic and gametophytic fronds, and these samples were also preconditioned for at least $3 \mathrm{wk}$. Infected fronds of the 2 life-history phases were incubated for at least 1 mo with the endophyte under conditions of slow growth (see above), and extensive penetration of the cortex had just begun

A field collection of Chondrus crispus was made in October; fronds broken at some point above the first dichotomy were collected from an intertidal population together with intact fronds. Measurements on these fronds were done within $2 \mathrm{~h}$ of collection; the broken fronds were punched in a narrow zone, 3 to $5 \mathrm{~mm}$ below the broken margins, while intact fronds were punched in the central portion, above the first dichotomy.

Analysis consisted of $t$-tests of the differences between 2 means from large samples, or single classification ANOVA (model I) with unequal sample size followed by a Tukey-Kramer test for multiple comparisons among pairs of means (Sokal \& Rohlf 1981).

Infection and feeding responses. The isopod Idotea baltica Pallas and the amphipod Gammarus oceanicus Segerstrale were obtained at the Finck Cove field station from tanks of Chondrus crispus, or from P. S. Shacklock's (NRCC, Halifax, NS, Canada) stocks of experimental animals.

Food preferences: Potential foods were simultaneously offered to individual grazers so that they could express a choice without interference from other individuals (Peterson \& Renaud 1989). The crustaceans were pretreated for at least $24 \mathrm{~h}$ with an abundant diet of the same combination of plants to be used in the experiments; this provided a similar short-term feeding history, and they were not starved before the experimental trials. Although generally used in feeding experiments, starvation produces undesirable trends where preference for items generally consumed poorly or not at all is increased (e.g. Nicotri 1980); furthermore, Idotea baltica was particularly sensitive to the absence of food, resorting to cannibalism. Each experimental grazer ( 8 to $12 \mathrm{~mm}$ long) was offered 2 or 3 pieces of fronds representing different food items of similar blotted wet weights (difference $<2 \%$ ). The experiments were done in $250 \mathrm{ml}$ flasks containing $175 \mathrm{ml}$ of $0.45 \mu \mathrm{m}$ membrane-filtered seawater with gentle aeration. Replicate flasks (control), containing combinations of algae similar to the experimental combination of food items but without herbivores, were included to quantify autogenic changes in the algae. Experimental and control replicates, covered by black plastic bags, were left for $24 \mathrm{~h}$ in a growth chamber set at $20^{\circ} \mathrm{C}$ (optimum feeding temperature, J. S. Craigie pers. comm.).

Algal combinations tested for preference by Idotea baltica were: (a) non-infected sporophytic Chondrus crispus vs non-infected gametophytic $C$. crispus, (b) non-infected sporophytic C. crispus vs Ulva sp., (c) non-infected gametophytic C. crispus vs Ulva sp., (d) non-infected sporophytic C. crispus vs sporophytic $C$. crispus infected by Acrochaete operculata, (e) sporophytic $C$. crispus infected by $A$. operculata vs Ulva sp., (f) sporophytic $C$. crispus infected by $A$. operculata vs non-infected sporophytic and gametophytic $C$, crispus (3-choice experiment), (g) noninfected gametophytic $C$. crispus vs gametophytic $C$. crispus infected by $A$. heteroclada, (h) non-infected sporophytic $C$. crispus vs sporophytic $C$. crispus infected by $A$. heteroclada. Fragments remaining from the 3-choice experiment were washed in several rinses of SFC medium, and incubated at experimental conditions for $1 \mathrm{mo}$ in individual $250 \mathrm{ml}$ flasks containing $175 \mathrm{ml}$ of medium changed weekly. The progress of regeneration or decay in each fragment was monitored and recorded. Combinations (d) and (g) were also tested with Gammarus oceanicus, following the same procedure.

At the end of each trial, experimental and control fronds were blotted and weighed. The difference in weight, whether gained or lost, is expressed as a percentage of the original weight, and analysed by t-tests where mean values for autogenic changes and the number of control replicates were incorporated in the calculations of the $t$ values (Peterson \& Renaud 1989) A Tukey test for multiple comparisons of means was used to analyse data from the 3-choice experiment.

Edibility: Individual grazers fed for a constant time on individually offered foods, and feeding rates of a grazer on alternative food items were compared as they are independent (Peterson \& Renaud 1989). The 
grazers were pretreated as described and then randomly assigned to flasks containing either infected or non-infected fronds. Controls without grazers were included to assess autogenic changes of the tested algae. Two combinations of food were used: (a) gametophytic Chondrus crispus infected by Acrochaete heteroclada vs non-infected gametophytic C. crispus, and (b) sporophytic $C$. crispus infected by $A$. operculata vs non-infected sporophytic $C$. crispus.

Experiments, done under the same conditions as the preference trials, lasted $24 \mathrm{~h}$. The food pieces were blotted, weighed and the values corrected for autogenic changes in the controls. Edibility was expressed as mg of alga consumed per mg of grazer per day, and comparisons for differences between means in each combination of food were performed by $t$-tests.

\section{RESULTS}

\section{Effect of infection on biomass accumulation and carrageenan yield}

Biomass accumulation following infection by Acrochaete operculata was related to the life-history phase of Chondrus crispus (Fig. 2a, b). Infected sporophytic apices increased an average of 11 times their original weight by the 40 th day of the experiment, while the average increase of control, non-infected apices, was 19 times (Fig. 2a). At the end of the experiment, the difference between infected and control groups $(p<0.001)$ persisted (Fig. 2a). Infected fronds were shorter and narrower than control ones, although no deformations or fragmentation was observed.

In the Acrochaete operculata-gametophyte combination (Fig. 2b), average biomass accumulations were of 67 and 74 times their original weight in control and infected thalli respectively, and were not significantly different $(p>0.5)$.

There was little biomass accumulation in fronds infected by Acrochaete heteroclada, regardless of lifehistory phase (Fig. 2C, d). Control apices had, by the 20th day of incubation, accumulated significantly $(p<0.001)$ greater mean biomass than the infected apices in the 2 phases of the host, and those differences were very apparent at the end of the experiments (Fig. 2c, d). Most fronds were overgrown by the endophyte, and some showed softening in the basal regions.

Carrageenan yield (Fig. 3) from the gametophytic fragments was not noticeably affected by infection with Acrochaete operculata; it was, however, slightly lower in sporophytic apices $(46.0 \%)$ compared with
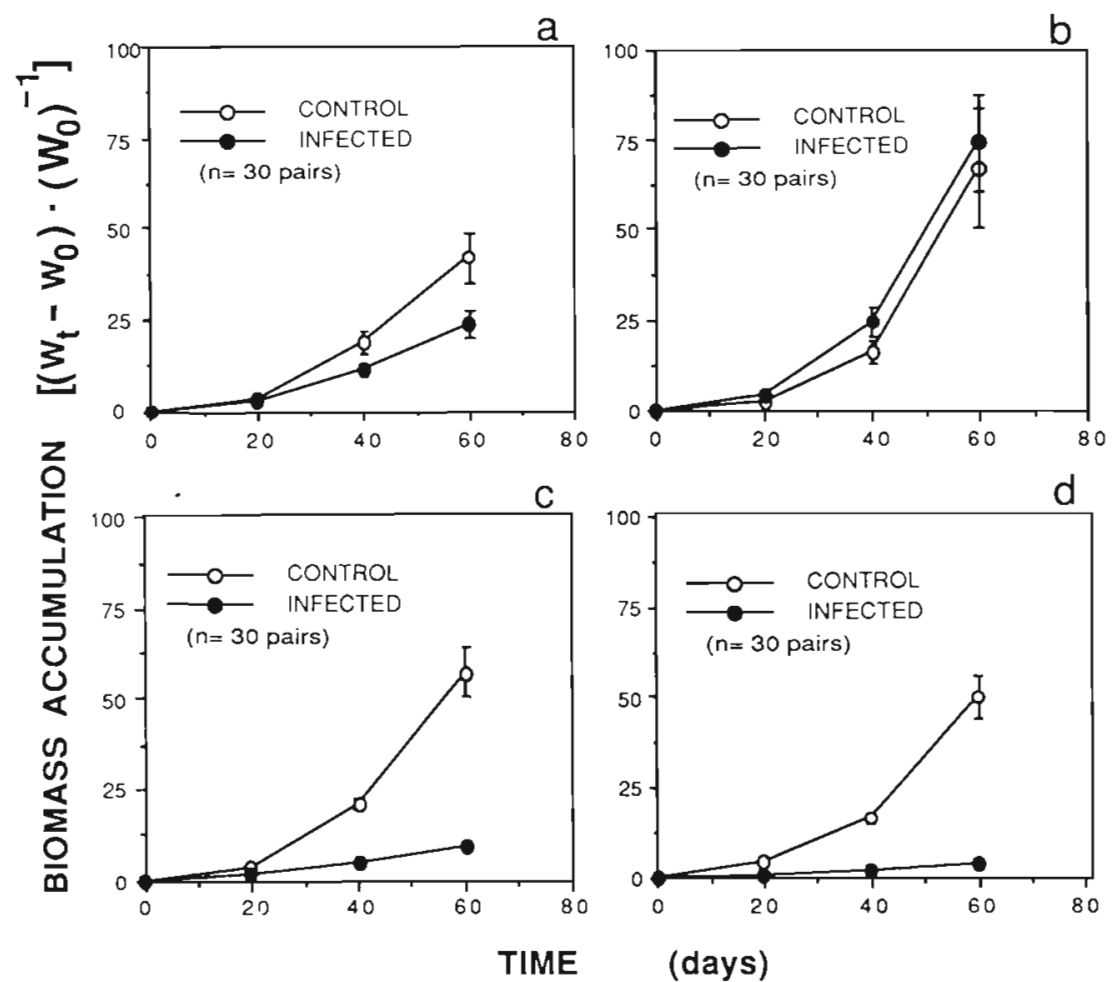

Fig. 2. Chondrus crispus. Effect of endophytic infection on biomass accumulation by apices. Control treatment consisted of uninfected apices of the corresponding life history phase of the host. Each point is a mean value for a given treatment; vertical bars indicate \pm 1 SE. (a) Sporophytic apices infected by Acrochaete operculata. (b) Gametophytic apices infected by $A$. operculata. (c) Sporophytic apices infected by A. heteroclada. (d) Gametophytic apices infected by A. heteroclada 


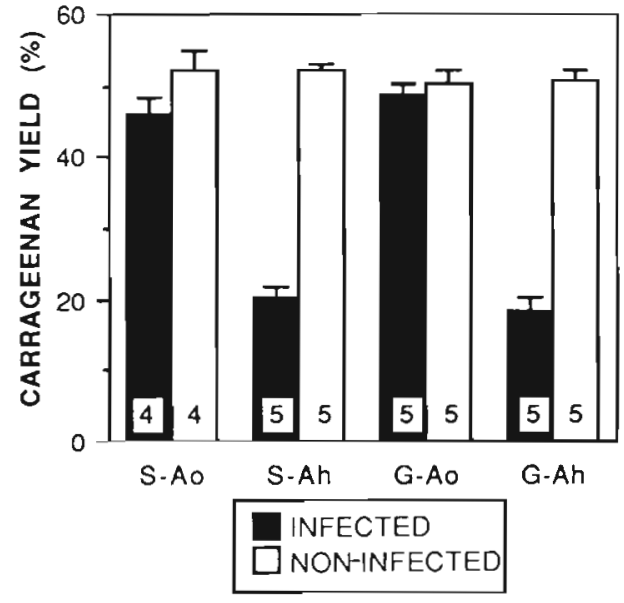

Fig. 3. Chondrus crispus. Carrageenan yield of fronds. S: sporophyte; G: gametophyte; Ao: Acrochaete operculata; Ah: A. heteroclada. Each bar is a mean value ( $\pm 1 \mathrm{SE}$ ), and number of replicates is shown at the base of each bar

controls (52\%). Infections by $A$. heteroclada resulted in considerably less carrageenan yield from both lifehistory phases, less than half of the amount obtained from controls (Fig. 3).

\section{Effect of infection on regeneration}

Regeneration of Chondrus crispus was affected by the density of Acrochaete operculata at the beginning of the experiment and was also related to the lifehistory phase of the infected host (Table 1). There was a low percentage of regeneration at high density and most sporophytic apices showed deformation of the cut edges, accompanied by softening. About $50 \%$ of the fragments with moderate densities of infection regenerated, producing 1 or 2 uprights, and less than $10 \%$ were noticeably softened. Even light infections affected regeneration, although there was no sign of softening of the tissue. At the end of the experiment, all control fragments regenerated, regardless of lifehistory phase of the host, or whether from the apical, central or basal regions of the fronds; these developed at least 1, and generally several (up to 32) upright initials. In no case was softening or discoloration of control fragments apparent.

Gametophytic fragments infected by Acrochaete operculata at moderate and low densities showed normal regeneration, as in controls (Table 1). Even in the heavily infected fronds, $82 \%$ of the fragments regenerated (Table 1), with usually 2 or more uprights. Regeneration along the cut edge was usual in fragments with moderate and light infections, and some of the heavily infected fragments formed uprights from any area of the cortex which did not appear to be affected by the endophyte.

Regeneration of Chondrus crispus was influenced by the density of Acrochaete heteroclada. There were, however, no marked differences between the 2 lifehistory phases (Table 1), and the results were similar to the regeneration pattern of sporophytic fragments infected by $A$. operculata. Regeneration from host tissue failed to occur or was minor at heavy densities of infection, most fragments became soft and cortical tissue of the host separated from the medulla. More than $90 \%$ of the fragments with moderate infection regenerated, usually forming 1 or 2 (up to 12) uprights, and with light infection regeneration was $100 \%$. There were no indications of softening in fragments with moderate or light densities of $A$. heteroclada.

\section{Effect of infection on toughness}

Significantly $(p<0.001)$ less force was required to perforate sporophytic fronds of Chondrus crispus infected by Acrochaete operculata (Fig. 4a) than non-

Table 1. Chondrus crispus. Effect of infection on regeneration. $n_{\mathrm{t}}=$ total number of fragments in each combination; $n_{\mathrm{r}}=$ number of fragments scored as regenerated for each combination. There was $100 \%$ regeneration by control fragments $(n=60$ to 64 for each combination)

\begin{tabular}{|c|c|c|c|c|c|c|c|c|c|}
\hline & \multicolumn{9}{|c|}{ Density of infection by Acrochaete operculata } \\
\hline & \multicolumn{3}{|c|}{ Heavy } & \multicolumn{3}{|c|}{ Moderate } & \multicolumn{3}{|c|}{ Light } \\
\hline & $n_{t}$ & $n_{\mathrm{r}}$ & $\%$ & $n_{1}$ & $n_{\mathrm{r}}$ & $\%$ & $n_{1}$ & $n_{r}$ & $\%$ \\
\hline Sporophyte & 99 & 5 & 5 & 105 & 49 & 47 & 104 & 89 & 86 \\
\hline \multirow[t]{4}{*}{ Gametophyte } & 66 & 54 & 82 & 38 & 38 & 100 & 39 & 39 & 100 \\
\hline & \multicolumn{9}{|c|}{ Density of infection by Acrochaete heteroclada } \\
\hline & \multicolumn{3}{|c|}{ Heavy } & \multicolumn{3}{|c|}{ Moderate } & \multicolumn{3}{|c|}{ Light } \\
\hline & $n_{i}$ & $n_{r}$ & $\%$ & $n_{1}$ & $n_{\mathrm{T}}$ & $\%$ & $n_{1}$ & $n_{r}$ & $\%$ \\
\hline Sporophyte & 132 & 0 & 0 & 122 & 1.15 & 94 & 120 & 120 & 100 \\
\hline Gametophyte & 128 & 6 & 5 & 140 & 119 & 85 & 120 & 120 & 100 \\
\hline
\end{tabular}


infected fronds. This ranged from $411 \mathrm{~g} \mathrm{~mm}^{-3}$ for fronds with light infection, only slightly less than noninfected fronds (Fig. 4a), to less than $50 \mathrm{~g} \mathrm{~mm}^{-3}$ for fronds with terminal infection.

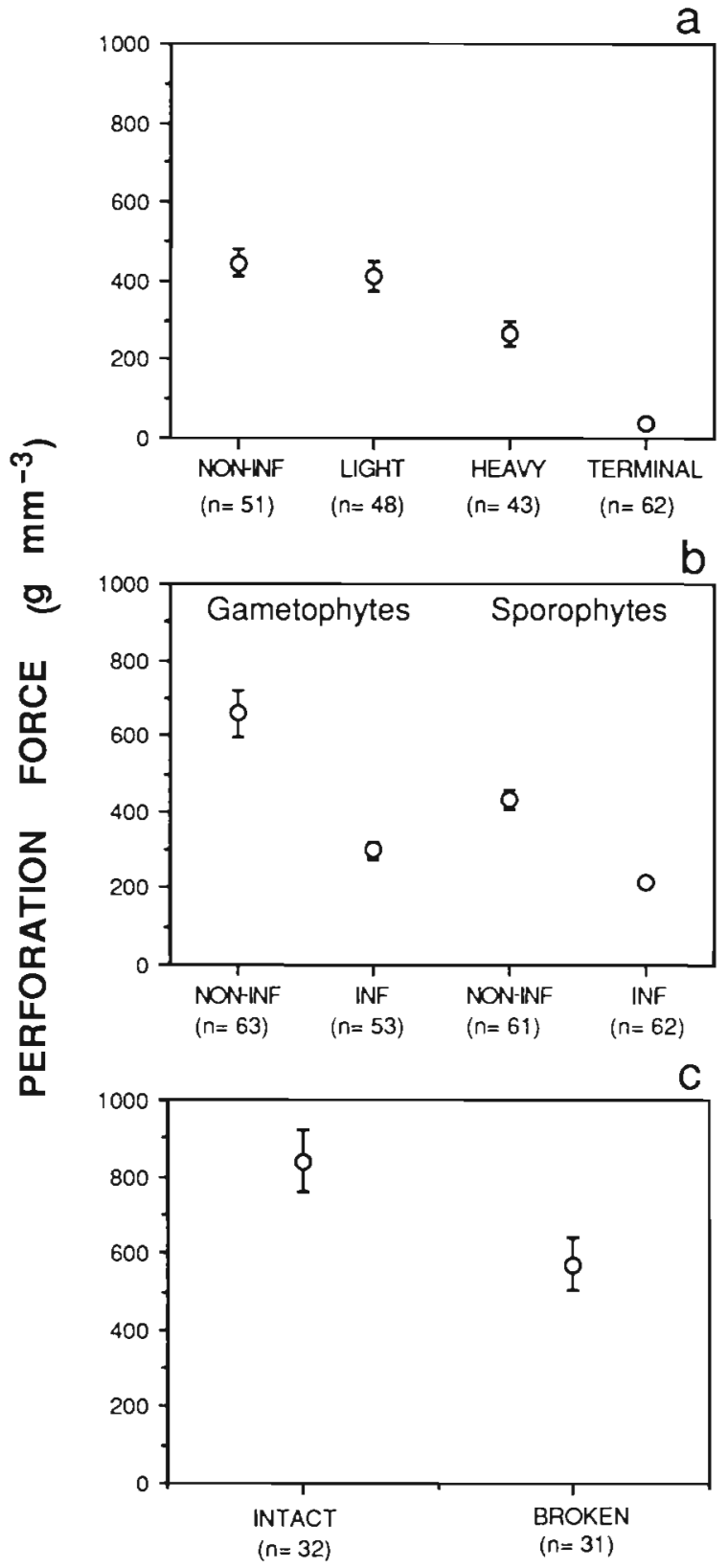

Fig. 4. Chondrus crispus. Effect of endophytic infection on toughness. Each point is the mean ( $99 \%$ confidence limits) force required to perforate the tissue. (a) Sporophytic $C$. crispus infected by Acrochaete operculata. Density = Light, heavy and terminal. 'Normal' toughness was obtained from non-infected sporophytic (NON-INF), laboratory-grown fronds. (b) Gametophytic and sporophytic C. crispus infected by $A$. heteroclada. Infected (INF) fronds are compared to non-infected (NON-INF) laboratory-grown controls for each phase of the host. (c) Perforation values for intact wild fronds of $C$. crispus and values from areas immediately subjacent to fracture points in broken fronds
The force required to perforate gametophytic and sporophytic fronds infected by Acrochaete heteroclada was significantly less $(\mathrm{p}<0.001)$ than the force required to perforate non-infected controls (Fig. 4b).

The force required to perforate wild fronds of Chondrus crispus was higher (Fig. 4C) than for laboratorygrown fronds. A mean force of $840 \mathrm{~g} \mathrm{~mm}^{-3}$ was required for intact fronds and a significantly lower force $(p<0.05)$ of less than $600 \mathrm{~g} \mathrm{~mm}^{-3}$ for zones near the fracture points in broken fronds. Areas tested in broken fronds were infected with various brown and green endophytes, and infections were heavier near the fracture point. Infections of intact fronds were minor or not apparent.

\section{Effect of infection on feeding responses}

The buccal appendages of Idotea baltica and Gammarus oceanicus (Fig. 5) appear well adapted to remove fragments from algae. The mandibles of $I$. baltica (Fig. 5a to c) are strong and each has 4 to 6 sharp tips (Fig 5b) that meet at the ventro-medial line (Fig. 5a). A discoid, ornamented molar process at the base of the mandible is only visible when removed from the individual (Fig. 5b). Adjacent appendages, like maxillae and maxillipeds, have sharp claw-like chitinous projections (Fig. 5c). G. oceanicus has buccal appendages similar in general structure to those of $I$. baltica (Fig $5 d$ to f). Mandibles are prominent, with a massive base and a double row of 4 to 6 sharp, pointed projections (Fig. 5d). As in 1 . baltica, an ornamented molar process, with concentrically arranged, sharpedged rings (Fig. 5e), is located at the base of each mandible. Auxiliary appendages associated with the mandibles terminate in sharp, elaborate needle-like projections (Fig. 5f). Mouth pieces of the 2 herbivores grazing on infected and non-infected Chondrus crispus showed a heavy load of algal fragments when observed directly (i.e. without cleaning prior to the sample preparation for SEM).

Results of the food preference trials are shown in Fig. 6. Idotea baltica preferred Ulva sp. over noninfected sporophytic (Fig. 6a) and gametophytic (Fig. 6b) Chondrus crispus. When the 2 life-history phases were offered as non-infected food, gametophytic fronds were preferred (Fig. 6c). When the alternative items were sporophytic fronds infected by Acrochaete operculata and non-infected sporophytic fronds, the isopods preferred infected fronds (Fig. 6d). Although $I$. baltica removed, on average, more algal biomass from $A$. operculata-infected sporophytic fronds than from Ulva sp. (Fig. 6e), this difference was not significant $(p>0.05)$. In the 3 -choice experiment, a clear ranking was established from the highly preferred sporophytic fronds infected by $A$. operculata to 


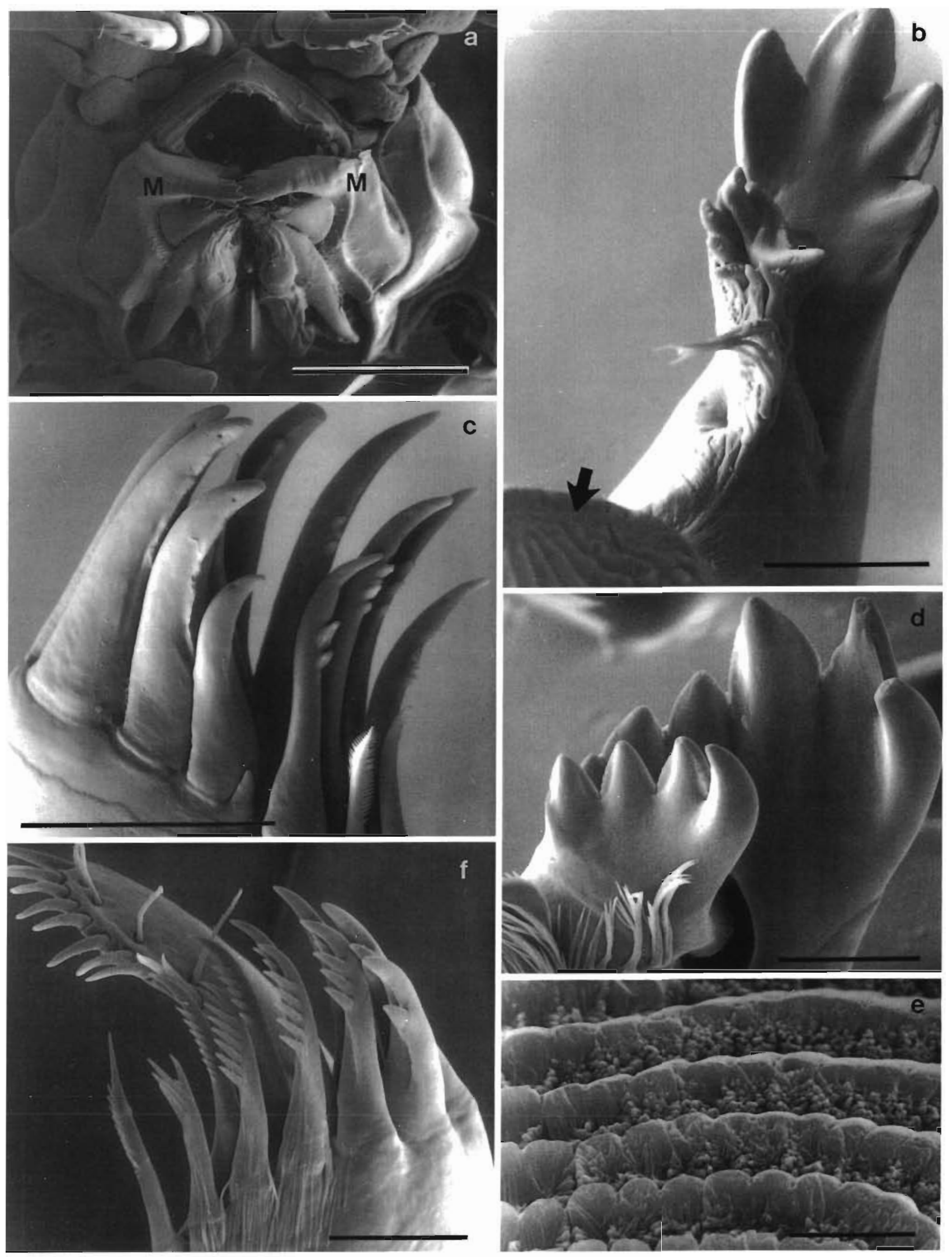




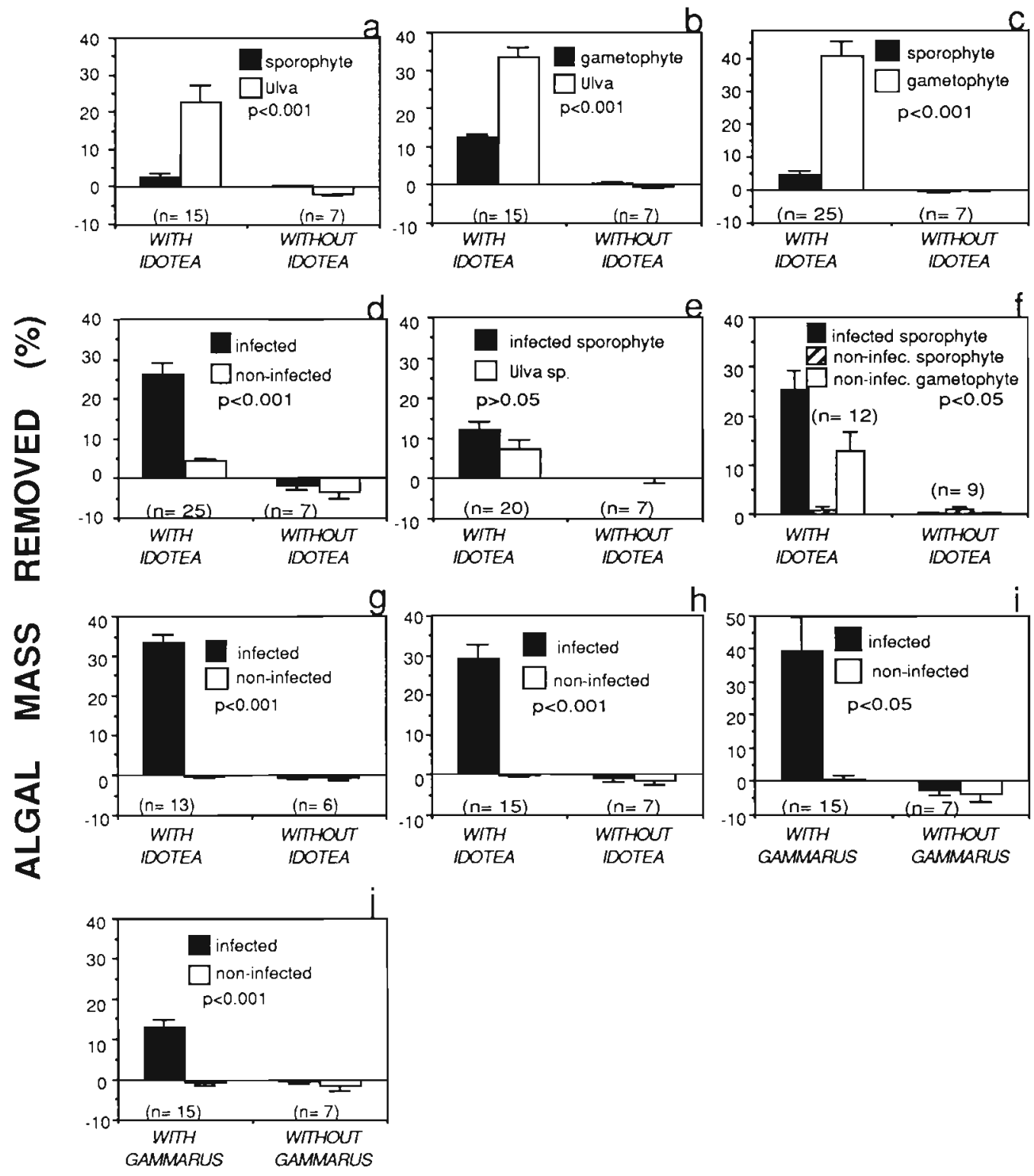

Fig. 6. Idotea baltica and Gammarus oceanicus. Food preferences. In all cases, values are mean ( \pm 1 SE) changes in algal biomass in each treatment. Negative values occur when tested specimens gained weight. (a to h) I. baltica. (a) Non-infected sporophytic fronds versus Ulva sp. (b) Non-infected gametophytic fronds versus Ulva sp. (c) Sporophytic versus gametophytic fronds, both uninfected. (d) Sporophytic fronds infected by Acrochaete operculata versus non-infected sporophytic fronds. (e) Sporophytic fronds infected by $A$. operculata versus Ulva sp. (f) Ranking of preferences in the 3-choice experiment where sporophytic fronds infected by $A$. operculata, and non-infected sporophytic and gametophytic fronds, were tested simultaneously. The $p$ value indicates the probability level used to test the differences on all possible pairs. (g) Sporophytic fronds infected by $A$. heteroclada versus non-infected sporophytic fronds. (h) Gametophytic fronds infected by A. heteroclada versus non-infected gametophytic fronds. (i to i) $G$. aceanicus. (i) Gametophytic fronds infected by $A$. heteroclada versus non infected gametophytic fronds.

(j) Sporophytic fronds infected by $A$. operculata versus non-infected sporophytic fronds

Fig. 5. Buccal appendages of $(\mathrm{a}, \mathrm{b}, \mathrm{c})$ Idotea baltica and (d, e, f) Gammarus oceanicus. (a) Ventral view of $I$. baltica showing the mouth region and the general arrangement of the buccal appendages. Note the mandibles (M) which meet at medial position. (b) Mandible with 4 pointed, sharp projections at the terminal end, and an ornamented molar process, located at the proximal end (arrow). (c) Claw-like terminal portion of a maxilla. (d) Mandible, showing a double row of teeth-like projections. (e) Detail of the discoid, ornamented molar process at the base of the mandible. (f) Claw-like terminal portion of a maxilla. Scales: $\mathrm{a}=1 \mathrm{~mm}$; $\mathrm{b}-\mathrm{d}, \mathrm{f}=100 \mu \mathrm{m} ; \mathrm{e}=10 \mu \mathrm{m}$ 
the least preferred item, non-infected sporophytic fronds (Fig. 6f). Similar results occurred with gametophytic and sporophytic fronds of $C$. crispus infected by A. heteroclada. In both sporophytic (Fig. 6g) and gametophytic (Fig. 6h) trials, fronds infected by $A$. heteroclada were preferred.

Gammarus oceanicus responded similarly to Idotea baltica when offered infected and non-infected fronds. This was demonstrated with gametophytic fronds infected by Acrochaete heteroclada (Fig. 6i) and sporophytic fronds infected by $A$. operculata (Fig. 6j); infected fronds were preferred over non-infected ones.

Complementary information obtained in the edibility experiments supports the food preferences displayed by Idotea baltica and Gammarus oceanicus. Fronds infected by either species of endophyte were eaten significantly more rapidly than non-infected counterparts. Feeding rates averaged more than half the wet weight of the herbivore per day when I. baltica was offered Acrochaete heteroclada-infected gametophytic Chondrus crispus (Fig. $7 \mathrm{a}$ ), and $40 \%$ of the herbivore's wet biomass per day in the Idotea/C. crispus- $A$. operculata combination (Fig. $7 \mathrm{~b}$ ). Consumption rates were consistently lower in $G$. oceanicus when feeding upon C. crispus infected by $A$. heteroclada (Fig. 7C) and A. operculata (Fig. $7 \mathrm{~d}$ ); those rates were, however, significantly higher than consumption rates for control, non-infected fronds.

The manner in which the herbivores grazed varied according to whether or not the fronds of Chondrus crispus were infected. This was particularly evident in the preference experiments done with Idotea baltica, where the crustaceans consistently bit the edges of non-infected fronds, leaving no marks on the flat surface. When feeding on infected fronds, however, grazing occurred mainly on the flat surface, with removal of extensive areas of cortical tissue. This had major effects on the regeneration of those fronds, as demonstrated by the incubation of fragments left after the 3-choice experiment. Discoloration, softening and decay of the infected fronds occurred rapidly, and a few hours were sufficient for complete breakdown to occur. All non-infected fronds, regardless of how extensively they had been consumed, regenerated many uprights along the damaged margins.

\section{DISCUSSION}

Chondrus crispus is adversely affected when infected by either Acrochaete operculata or A. heteroclada, and these effects can be related to the species of endophyte involved and the life-history phase of the host. Density of infection determines the degree to which features, like regeneration and toughness, are affected.

Biomass acquisition in Chondrus crispus results from apical (i.e. mainly elongation) and marginal (i.e. mainly widening) meristematic activity (Chopin \& Floc'h 1987), and it is negatively affected as host-cell death gradually increases during consolidation of the infection (Correa 1990). This explains the observations

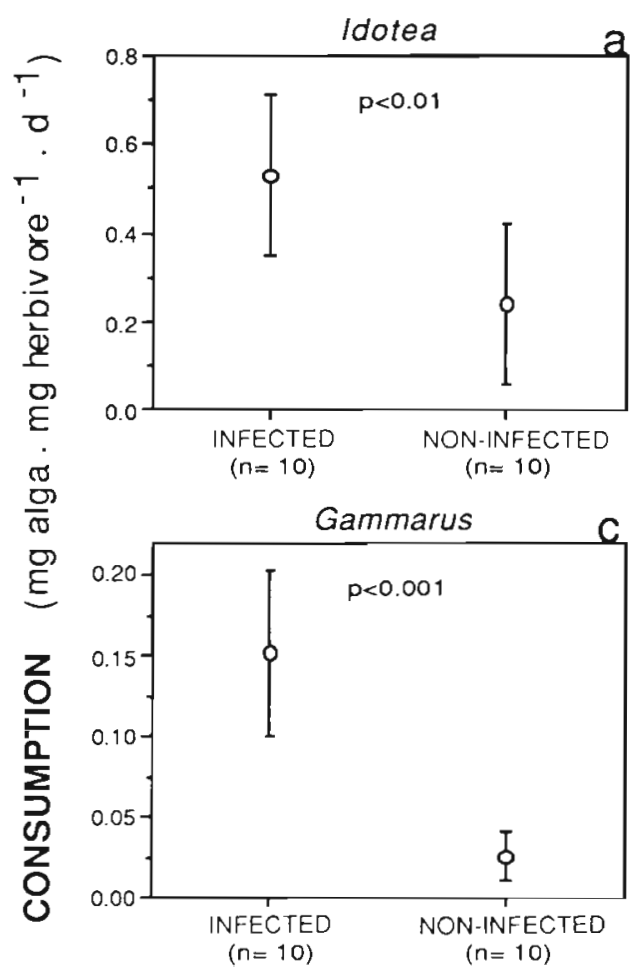

$(n=10)$
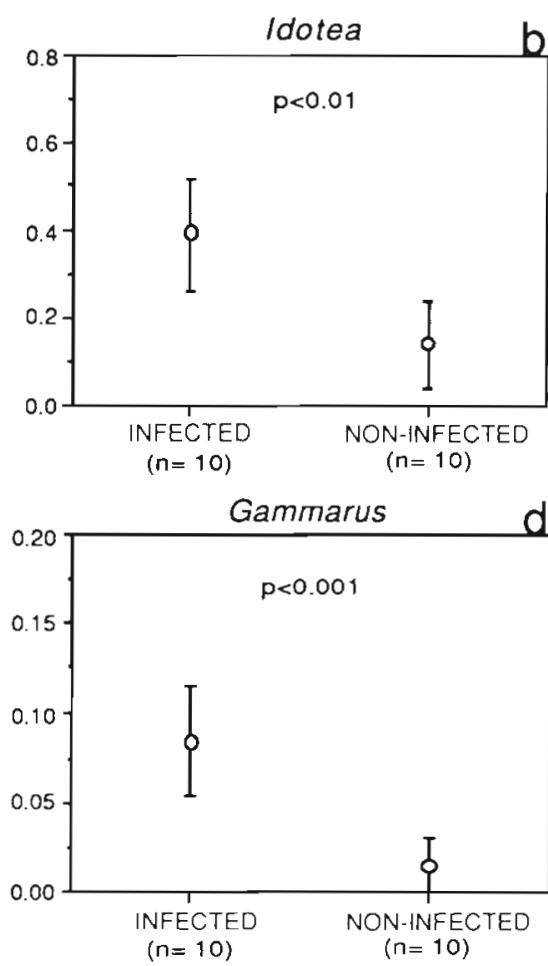

Fig. 7. Effect of endophytic infection on edibility of Chondrus crispus by Idotea baltica and Gammarus oceanicus. Points are mean consumption $(99 \%$ confidence limit) in each treatment. (a) Gametophytic fronds infected by Acrochaete heteroclada, and non-infected fronds, consumed by 1 . baltica. (b) Sporophytic fronds infected by $A$. operculata, and non-infected sporophytic fronds, consumed by $I$. baltica. (c) Algal material as in (a), consumed by $G$. oceanicus. (d) Algal material as in (b), consumed by G. oceanicus 
of fronds infected by Acrochaete operculata being shorter and narrower than non-infected controls. The branching pattern of these infected fronds, however, was normal as the apical meristem was not completely overgrown by $A$. operculata in the fast-growing experimental conditions. Subapical infections, on the other hand, consolidated rapidly in sporophytic fronds, causing cessation of frond widening as a result of massive cell disruption at the marginal meristems (Correa 1990). Parasitic red algae have been reported to reduce growth of their hosts (Nonomura 1979. Apt 1984), but that was not the result of extensive cellular damage as in the $C$. crispus-A. operculata association. On the other hand, carrageenan yields of Hypnea musciformis (Wulfen) Lamouroux were not affected by parasitic infections (Apt 1984), whereas with infected C. crispus carrageenan yields were low. Infections by A. operculata resulted in reduced carrageenan yields in only sporophytic fronds; this pathogen had little effect on the gametophytic generation.

Wound healing, an obligatory step that precedes regeneration, involves dedifferentiation of cortical and medullary cells which become meristematic (Fulcher \& McCully 1969, Fagerberg \& Dawes 1976, AzanzaCorrales \& Dawes 1989). As endophytic filaments of Acrochaete operculata become more numerous in the cortex, sporangium mother cells enlarge and more host cells undergo degenerative changes (Correa 1990). It is unlikely that the dedifferentation process at the margins of infected sporophytic tissue can occur with disrupted, non-functional host cells. Gametophytic fronds of Chondrus crispus infected by $A$. operculata were less affected at the cellular level than sporophytic fronds (Correa 1990), and this permitted normal wound healing, regeneration, elongation and expansion along the margins as in non-infected fronds (cf. Chopin \& Floc'h 1987).

Acrochaete heteroclada affected similarly both lifehistory generations of Chondrus crispus, and prior to penetration by the endophyte, disruption of host cells is negligible (Correa 1990). Initial low biomass accumulation in infected fronds is interpreted as the filtering of nutrients, light or both by the endophyte (e.g. Sand-Jensen 1977, Cambridge et al. 1986, SandJensen \& Revsbech 1987). With subsequent development of $A$. heteroclada, further dysfunctions of the host occurred due to invasion of the cortical tissue (Correa 1990), which eventually results in the demise of infected fronds.

The leathery texture of Chondrus crispus likely results from spatial arrangement of the cells combined with the physico-chemical properties of the cell wall including the immediate cell wall and intercellular matrix (Kloareg \& Quatrano 1988). Consequently, any factor altering these properties will result in changes in the biomechanical characteristics of the fronds. This was undoubtedly the effect of Acrochaete operculata on sporophytic and $A$. heteroclada on both sporophytic and gametophytic $C$. crispus, where the destructive effects on host cells and tissue by the endophytes (Correa 1990) certainly contributed to weakening of the fronds. Lytic enzymes leaking from damaged host cells may also become part of the process of softening the tissues of $C$. crispus, aggravating the disruptive action of the endophytes. Secondary bacterial infection may also contribute to digestion of extensive areas of cortical and medullary intercellular matrix of the host (Correa 1990).

Field-collected Chondrus crispus confirmed results of laboratory-infected material; areas below fracture points in broken fronds were heavily infected by brown and green endophytes, and were consistently softer than intact, lightly or non-infected fronds. These infections were extensive, and their patterns of development in the host (Correa 1990, Correa \& McLachlan 1991) indicate that they likely developed prior to fractures and were not secondary to them. It is unclear why toughness was higher for wild $C$. crispus than for laboratory-grown fronds, although growth conditions and their effect on carrageenan content may explain such a difference (Neish et al, 1977, McCandless \& Craigie 1979). Wild plants were collected in the autumn, when levels of nitrate and phosphate in the water are relatively low (Mathieson \& Burns 1975), and the total carrageenan content maximal (Chopin 1986). On the other hand, laboratory-grown fronds received frequent changes of seawater enriched with nitrate and phosphate, which probably prevented the accumulation of carrageenan due, for example, to nitrogen depletion (Neish et al. 1977). Furthermore, the high pH characteristic of laboratory cultures produces soft, floppy fronds (Simpson et al. 1978)

Chondrus crispus is regarded as a poorly preferred food item because of its leathery texture (Lubchenco 1978, Lubchenco \& Menge 1978). We confirm this for Idotea baltica when offered non-infected tissue of either phase together with Ulvasp. Similar preferential grazing of Enteromorpha, a close relative of Ulva, by I. baltica in the presence of $C$. crispus has been demonstrated by Shacklock \& Doyle (1983). Endophytic infections of sporophytic fronds by Acrochaete operculata increased $C$. crispus attractiveness to I. baltica to levels equivalent to Ulva. Preference extended to gametophytic and sporophytic fronds infected with $A$. heteroclada. Gammarus oceanicus behaved similarly to $I$. baltica, suggesting a common response to algae infected by endophytes among these grazers. Ours is the first report of experimental evidence for changes in feeding responses by marine herbivores resulting from algal endophytic infections, 
and we stress the necessity of rigorous examination for algal endophytes before food-preference experiments are undertaken. Edibility (sensu Watson \& Norton $1985,1987)$ experiments support the food preference data, and indicate that infected hosts are consumed more rapidly than non-infected fronds. It is not clear, however, why consumption rates for $G$. oceanicus were much lower than those for I. baltica. As the buccal parts seem similar, differences in consumption rates may represent physiological dissimilarities between the 2 grazers.

Two factors may determine preferential feeding. Firstly, grazers may be attracted to infected fronds as they become softer during algal endophytic infections and subsequent secondary bacterial invasion. In sporophytic fronds, infections by Acrochaete operculata were heavier at the base (i.e. softer areas) than at the apices (i.e. tougher areas); tissue removed by grazers was mainly from the basal area and grazing marks were rarely observed at the apical portions. A similar pattern of grazing marks was commonly found on heavily infected, field-collected fronds of Chondrus crispus (Correa unpubl.). Switching of feeding by Idotea baltica and Gammarus oceanicus from edges of non-infected fronds to deep browsing on the flat surface of heavily infected areas also suggests a response to softening of the tissues. Secondly, preferential feeding may involve the release of metabolic substances from the endophytes which are phagostimulants. Phagostimulatory properties have been demonstrated for a number of algal products which induce feeding responses in fishes, gastropods and crustacean herbivores (Carr \& Derby 1986, Rittshof \& Bonaventura 1986, Sakata et al. 1988). Tissue softening and release of phagostimulants certainly may simultaneously influence the behavior of grazers, although it is difficult to separate experimentally one from the other. In fact, it may prove to be impossible, as recent studies indicate that the senses of taste, touch and smell, anatomically distinct in terrestrial vertebrates, form a continuum in marine sensory systems (Rittschof \& Bonaventura 1986). Preliminary information shows that $I$. baltica detects substances released by noninfected, disrupted C. crispus tissue embedded in agar blocks, and also indicates that this grazer is stimulated by mixtures of phagostimulatory substances from both host and endophyte (Correa unpubl.). Similar reactions have been reported for other crustaceans, where mixtures of substances result in stronger feeding responses than when administered singly (Carr \& Derby 1986).

Crustacean mesoherbivores prefer epiphytic components of host-epiphyte associations (e.g. Shacklock \& Doyle 1983, D'Antonio 1985, Brawley \& Fei 1987), and generally minor damage results to the basiphyte
Some overgrazing, however, may result in damage to the host (Shacklock \& Doyle 1983, Craigie \& Shacklock 1989). Grazing of hosts infected by endophytes, however, always results in biomass losses from the host, which aggravates regeneration and facilitates secondary infections by bacteria (Correa 1990).

Chondrus crispus is a perennial species and occupies major areas of primary space. Its persistence is determined by interactions with its physical environment, with organisms that compete for space (Chapman 1986, Dudgeon et al. 1989), and with other organisms that use C. crispus as substratum or food (Prince \& Kingsbury 1973, Pybus 1977, Shacklock \& Croft 1981 , Shacklock \& Doyle 1983). The extent to which the negative effects of infection by 2 common green-algal endophytes tested in the laboratory are expressed in wild populations of $C$. crispus, and the importance of endophytism to the population biology of C. crispus, remain to be determined. It is, however, reasonable to assume that factors like those discussed in the present study have an impact on the longevity and recovery (regeneration) of the fronds. Wave action is, for example, a major agent of disturbance (Koehl 1986، Biedka et al. 1987, Denny 1987, 1988, Denny et al. 1989). Softening of fronds of C. crispus by endophytic infections likely facilitates fractures by wave action, and furthermore, when fronds are grazed, the removed biomass will accelerate the fracture process by producing flaws on the surface where the wave forces concentrate and amplify (Biedka et al. 1987, Denny et al. 1989). The architecture of C. crispus, with an extremely narrow stipe attached to the holdfast, suggests that fractures will occur more frequently at the stipeholdfast interface (McLachlan et al. 1989); however, up to $30 \%$ of randomly collected fronds from intertidal populations of $C$. crispus in Nova Scotia were broken above the first dichotomy (McLachlan unpubl.). This indicates that fractures occurred at a point weaker than the holdfast-stipe interface. The force required to break intact, non-infected fronds above the first dichotomy is several times the force needed to separate the frond from the holdfast, reported to be 4 to $5 \mathrm{~N} \mathrm{~mm}^{-2}$ (McLachlan et al. 1989). Breakage above the first dichotomy must, therefore, result from softening of the tissue or flaws or both. This is supported by observations of endophytic infections and grazing marks commonly found at the fracture points in fieldcollected fronds (Correa unpubl.). Moreover, when endophytic infections at the fracture site are heavy, regeneration will be suppressed and the frond lost from the population.

A major consideration of the results of our study is the differential susceptibility of gametophytic and sporophytic phases of Chondrus crispus to infections by Acrochaete operculata (Correa \& McLachlan 1991). 
The negative effects of the infection reported here should be integrated into possible explanations for gametophytic dominance in some populations of C. crispus (Bhattacharya 1985).

Chondrus crispus is a 'domesticated' species and is susceptible to an array of pathogens, some of which might be of little consequence under natural conditions. Acrochaete operculata and A. heteroclada pose major threats to large-scale cultivation of $C$. crispus, lessening production and carrageenan yields and resulting in potential contamination of the extracts. Endophytes also facilitate secondary infections leading to softening of tissue and stimulating selective grazing by crustacean associated with cultivated $C$. crispus. The last 3 named factors may accelerate the process of frond fragmentation, which could result in significant biomass losses (Craigie \& Shacklock 1989, Craigie 1990). The use of crustacean grazers has been suggested as a biological control for epiphytes in a number of small- and large-scale algal culture systems (Shacklock \& Doyle 1983, Brawley \& Fei 1987), although these could result in more damage than benefits if endophytes or epi/endophytes are involved. Contamination of the carrageenan extracts is an aspect that needs further attention. Carrageenan extraction procedures (Correa unpubl.) using $A$. heteroclada or A. operculata from unialgal cultures yield a whitish, finely granular material (ca $9 \%$ of dry wt). This material might interfere with the properties of carrageenan when infected fronds are used for extraction. The negative effect of endophytic infections on regeneration may represent an additional problem for farmed seaweeds, including C. crispus, whose propagation is based on vegetative propagation of clonal material.

In summary, the negative effects of infection by the 2 endophytes on various aspects of host performance reported here, together with the severe damage at cellular level demonstrated by Correa (1990), lead to the conclusion that Acrochaete operculata and A. heteroclada are pathogens of Chondrus crispus.

Acknowledgements. This study was in part supported by a NSERC grant to J.L.McL. J.A.C. thanks the National Research Council for use of laboratory facilities during the tenure of this research, and the Pontificia Universidad Católica de Chile for the leave of absence during his graduate studies. We thank P. Shacklock, L. Staples and J. S. Craigie for sharing their unpublished information on grazing of Chondrus crispus by Gammarus oceanicus and Idotea baltica. We thank A. R. O. Chapman for his wise advice and for reviewing early versions of this manuscript, and also appreciate the suggestions and comments of 2 anonymous reviewers.

\section{LITERATURE CITED}

Andrews, J. H. (1977). Observations on the pathology of seaweeds in the Pacific Northwest. Can. J. Bot. 55:1019-1027

Apt, K. E. (1984). Effects of the symbiotic red alga Hypneocolax stellaris on its host Hypnea musciformis (Hypneaceae, Gigartinales). J. Phycol. 20: 148-150

Apt, K. E. (1988). Ethiology and development of hyperplasia induced by Streblonema sp. (Phaeophyta) on members of the Laminariales (Phaeophyta). J. Phycol. 24: 28-34

Azanza-Corrales, R., Dawes, C. J. (1989). Wound healing in cultured Eucheuma alvarezii var tambalang Doty. Botanica mar. 32: 229-234

Bhattacharya, D. (1985). The demography of fronds of Chondrus crispus Stackhouse. J. exp. mar. Biol. Ecol. 91: 217-23.

Biedka, R. F., Gosline, J. M., De Wreede, R. E. (1987). Biomechanical analysis of wave-induced mortality in the marine alga Pterygophora californica. Mar. Ecol. Prog. Ser. 36: $136-170$

Brawley, S. H., Fei, X. G. (1987). Studies of mesoherbivory in aquaria and in an unbarricaded mariculture farm on the Chinese coast. J. Phycol. 23: 614-623

Cambridge, M. L., Chiffing. A. W., Brittan, C., Moore, L., McComb, A. J. (1986). The loss of seagrass in Cockburn Sound, Western Australia. II. Possible causes of seagrass decline. Aquat. Bot. 24: 269-285

Carpenter, R. C. (1990). Competition among marine macroalgae: a physiological perspective. J. Phycol. 26: 6-12

Carr, W. E. S., Derby, C. D. (1986). Chemically stimulated feeding behavior in marine animals. Importance of chemical mixtures and involvement of mixture interactions. J. chem. Ecol. 12: 989-1011

Chapman, A. R. O. (1986). Population and community ecology of seaweeds. Adv. mar. Biol. 23: 1-161

Chen, L. C-M., McLachlan, J. (1972). The life history of Chondrus crispus in culture. Can J. Bot. 50: 1055-1060

Chopin, T (1986). The red alga Chondrus crispus Stackhouse (Irish moss) and carrageenans - a review. Can. Tech. Rep. Fish. Aquat. Sci. 1514: 1-68

Chopin, T., Floc'h, J.-Y (1987). Seasonal variations of growth in the red alga Chondrus crispus on the Atlantic French coast. 1. A new approach by fluorescence labelling. Can. J. Bot. 65: 1014-1018

Correa, J. A. (1990). Pigmented algal endophytes of Chondrus crispus Stackhouse: host specificity, fine structure and effects on host performance in infections by Acrochaete operculata Correa \& Nielsen and A heteroclada Correa \& Nielsen. Ph.D thesis, Dalhousie University, Halifax

Correa, J. A., Nielsen, R., Grund, D. W., McLachlan, J. (1987). Endophytic algae of Irish moss (Chondrus crispus Stackh.). Hydrobiologia 151/152: 223-228

Correa, J. A., Nielsen, R., Grund, D. W. (1988). Endophytic algae of Chondrus crispus (Rhodophyta). II. Acrochaete heteroclada sp. nov., A. operculata sp. nov., and Phaeophila dendroides (Chlorophyta). J. Phycol. 24: 528-539

Correa, J. A., McLachlan J. (1991). Endophytic algae of Chondrus crispus (Rhodophyta). III. Host-specificity. J. Phycol. 27: 448-459

Court, G. J. (1980). Photosynthesis and translocation studies of Laurencia spectabilis and its symbiont Janczewskia gardneri (Rhodophyceae). J. Phycol. 16: 270-279

Craigie, J. S. (1990). Irish moss cultivation: some reflections. In: Yarish, C., Penniman, C. A., Van Patten, P. (eds.) Economically important marine plants of the Atlantic. Their biology and cultivation. Connecticut Sea Grant College Program, Marine Sciences Institute, University of Connecticut, Groton, Connecticut, p. 37-52 
Craigie, J. S., Leigh, C. (1978). Carrageenans and agars. In: Hellebust, J. A., Craigie, J. S. (eds.) Handbook of phycological methods. Physiological and biochemical methods Cambridge University Press, Cambridge, p. 109-131

Craigie, J. S., Shacklock, P. F. (1989). Culture of Irish moss. In: Boghen, A. D. (ed.) Cold water aquaculture in Atlantic Canada. The Canadian Institute for Research on Regional Development, University of Moncton, Moncton, N.B., p. 243-270

D'Antonio, C. (1985). Epiphytes on the rocky intertidal red alga Rhodomela larix (Turner) C. Agardh: negative effects on the host and food for herbivores?. J. exp. mar. Biol. ECol. 86: 197-218

Denny, M. W. (1987). Lift as a mechanism of patch initiation in mussel beds. J. exp. mar. Biol. Ecol. 113: 231-245

Denny, M. W. (1988). Biology and the mechanics of the waveswept environment. Princeton University Press, Princeton

Denny, M. W., Daniel, T. L., Koehl, M. A. R. (1985). Mechanical limits to size in wave-swept organisms. Ecol. Monogr. 55: $69-102$

Denny, M. W., Brown, V., Carrington, E., Kraemer, G., Miller, A. (1989). Fracture mechanics and the survival of wave. swept macroalgae. J exp. mar Biol. Ecol. 127: 211-228

Dixon, J., Schroeter, S.C., Kastendiek, J. (1981). Effects of the encrusting bryozoan, Membranipora membranacea, on the loss of blades and fronds by the giant kelp, Macrocystis pyrifera (Laminariales). J. Phycol. 17: 341-345

Ducker, S. C., Knox, R. B. (1984). Epiphytism at the cellular level with special reference to algal epiphytes. In Linskens, H. F., Heslop-Harrison, J (eds.) Cellular interactions. Encyclopedia of plant physiology, N. S., Vol. 17 Springer-Verlag, Berlin, p. 113-123

Dudgeon, S. R., Davison, I. R., Vadas, R. L. (1989). Effect of freezing on photosynthesis of intertidal macroalgae: relative tolerance of Chondrus crispus and Mastocarpus stellatus (Rhodophyta). Mar. Biol. 101: 107-114

Fagerberg, W. R., Dawes, C. J. (1976). Studies on Sargassum. I. A light microscopic examination of the wound regeneration process in mature stipes of S. filipendula. Am. J. Bot. 63: $110-119$

Fulcher, R. G., McCully, M. E. (1969). Histological studies on the genus Fucus. IV. Regeneration and adventive embryony. Can. J. Bot. 47: 1643-1649

Goff, L. J. (1976). The biology of Harveyella mirabilis (Cryptonemiales, Rhodophyceae). V. Host responses to parasite infection. J. Phycol. 12: 313-328

Goff, L. J. (1982). The biology of parasitic red algae. In Round, F. E., Chapman, D. J. (eds.) Progress in phycological research, Vol. 1 Elsevier, New York, p. 289-369

Goring, D. A. I. (1956). A semimicro gelometer. Can. J. Tech. 34: $53-59$

Kloareg, B., Quatrano, R. S. (1988). Structure of the cell walls of marine algae and ecophysiological functions of the matrix polysaccharides. Oceanogr. mar. Biol. Ann. Rev. 26: 259-315

Koehl, M. A. R. (1986). Seaweeds in moving water: form and mechanical function. [n: Givnish, I. J. (ed.) On the economy of plant form and function. Cambridge University Press, Cambridge, p. 603-634

Kremer, B. P. (1983). Carbon economy and nutrition of the alloparasitic red alga Harveyella mirabilis. Mar Biol. 76 : 231. -239

Kugrens, P., West, J. A. (1973). The ultrastructure of the alloparasitic red alga Choreocolax polysiphoniae. Phycologia 12: $175-186$

Littler, M. M., Littler, D. S. (1980). The evolution of thallus form and survival strategies in benthic marine macro- algae: field and laboratory tests of a functional form model. Am. Nat. 116: 25-44

Lubchenco, J. (1978). Plant species diversity in a marine intertidal community: importance of herbivore food preference and algal competitive abilities. Am. Nat. 112 $23-39$

Lubchenco, J., Menge, B. A. (1978). Community development and persistence in a low rocky intertidal zone. Ecol. Monogr. 59: 67-94

Mathieson, A. C., Burns, R. L. (1975). Ecological studies of economic red algae. 5. Growth and reproduction of natural and harvested populations of Chondrus crispus Stackhouse in New Hampshire. J. exp. mar. Biol. Ecol. 17: $137-156$

McCandless, E. L., Craigie, J. S. (1979). Sulfated polysaccharides in red and brown algae. Ann. Rev. Plant. Physiol. 30: 41-53

McLachlan, J., Quinn, J., MacDougall, C. (1989). The structure of the plant of Chondrus crispus Stackhouse (Irish moss). J. appl. Phycol. 1: 311-317

Neish, A. C., Shacklock, P. F., Fox, C. H., Simpson, F. J. (1977). The cultivation of Chondrus crispus. Factors affecting growth under greenhouse conditions. Can. J. Bot. 55: $2263-2271$

Nicotri, M. E. (1980). Factors involved in herbivore food preference. J. exp. mar. Biol. Ecol. 42: 13-26

Nielsen, R. (1979). Culture studies on the type species of Acrochaete, Bolbocoleon and Entocladia (Chaetophoraceae, Chlorophyceae). Bot. Not. 132: 441-449

Nielsen, R., McLachlan, J. (1986). Investigations of the marine algae of Nova Scotia. XVI. The occurrence of small green algae. Can. J. Bot. 64: 808-814

Nonomura, A. M. (1979). Development of Janczewskia morimotoi (Ceramiales, Rhodophyceae). J. Phycol. 15: 154-162

O'Kelly, C. J. (1982). Observations on marine Chaetophoraceae (Chlorophyta). III. The structure, reproduction and life history of Endophyton ramosum. Phycologia 21: $247-257$

Oswald, R. C., Seed, R. (1986). Organization and seasonal progression within the epifaunal communities of coastal macroalgae. Cah. Biol. mar. 27: 29-40

Peterson, C. H., Renaud, P. E. (1989). Analysis of feeding preference experiments. Oecologia 80: 82-86

Prince, J. S., Kingsbury, J. M. (1973). The ecology of Chondrus crispus at Plymouth, Massachusetts. 2. Field studies. Am. J. Bot. 60: 964-975

Pybus, C. (1977). The ecology of Chondrus crispus and Gigartina stellata (Rhodophyta) in Galway Bay. J. mar. biol. Ass. U.K. 57: 609-628

Rittshof, D., Bonaventura, J. (1986). Macromolecular cues in marine systems. J. chem. Ecol. 12: 1013-1023

Russell, G. (1983). Formation of an ectocarpoid epiflora on blades of Laminaria digitata. Mar. Ecol. Prog. Ser. 11: $181-187$

Sakata, K. Sakura, T., Ina, K. (1988). Algal phagostimulants for marine herbivorous gastropods. J. chem. Ecol. 14: $1405-1416$

Sand-Jensen, K. (1977). Effect of epiphytes on eelgrass photosynthesis. Aquat. Bot. 3: 55-63

Sand-Jensen, K., Revsbech, N. P. (1987). Photosynthesis and light adaptation in epiphyte-macrophyte associations measured by oxygen microelectrodes. Limnol. Oceanogr. 32: $452-457$

Shacklock, P. F., Croft, G. B. (1981). Effects of grazers on Chondrus crispus in culture. Aquaculture 22: 331-342

Shacklock, P. F., Doyle, R. W. (1983). Control of epiphytes in seaweed cultures using grazers. Aquaculture 31 141-151 
Simpson, F. J., Neish, A. C., Shacklock, P. F., Robson, D. R. (1978). The cultivation of Chondrus crispus: effect of $\mathrm{pH}$ on growth and production of carrageenan. Botanica mar. 21: $229-235$

Sokal, R. R., Rohlf, F. J. (1981), Biometry. W. H. Freeman and Co., New York

Tam, C. E., Cole, K. M., Garbary, D. (1987). In situ and in vitro studies on the endophytic red algae Audouinella porphyrae and A. vaga (Acrochaetiales). Can. J. Bot. 65: $532-538$

Terry, L. A., Edyvean, R. G. J. (1981). Microalgae and corrosion. Botanica mar. 24: 177-183

This article was submitted to the editor
Wahl, M. (1989). Marine epibiosis. I. Fouling and antifouling: some basic aspects. Mar. Ecol. Prog. Ser. 58: $175-189$

Watson, D. C., Norton, T. A. (1985). Dietary preferences of the common periwinkle, Littorina littorea (L.). J. exp mar. Biol. Ecol. 88: 193-211

Watson, D. C., Norton, T A. (1987). The habitat and feeding preferences of Littorina obtusata (L.) and L. mariae Sacchi et Rastelli. J. exp. mar. Biol. Ecol. 112: 61-72

Yoshida, T., Akiyama, K. (1979). Streblonema (Phaeophyta) infection in the frond of cultivated Undaria (Phaeophyceae). Proc. Int. Seaweed Symp. 9: 219-223

Manuscript first received: October 8,1991

Revised version accepted: January 22, 1992 